\title{
RNA interference-based antiviral immune response against the salivary gland hypertrophy virus in Glossina pallidipes
}

Irene K. Meki ${ }^{1,2}$, Henry M. Kariithi ${ }^{1,3}$, Andrew G. Parker ${ }^{1}$, Marc J B Vreysen', Vera I D Ros², Just M Vlak², Monique M van Oers ${ }^{2}$ and Adly M. M. Abd-Alla ${ }^{1^{*}}$

\begin{abstract}
Background: Glossina pallidipes salivary gland hypertrophy virus (GpSGHV; Hytrosaviridae) is a non-occluded dsDNA virus that specifically infects the adult stages of the hematophagous tsetse flies (Glossina species, Diptera: Glossinidae). GpSGHV infections are usually asymptomatic, but unknown factors can result to a switch to acute symptomatic infection, which is characterized by the salivary gland hypertrophy (SGH) syndrome associated with decreased fecundity that can ultimately lead to a colony collapse. It is uncertain how GpSGHV is maintained amongst Glossina spp. populations but RNA interference (RNAi) machinery, a conserved antiviral defense in insects, is hypothesized to be amongst the host's mechanisms to maintain the GpSGHV in asymptomatic (persistent or latent) infection state. Here, we investigated the involvement of RNAi during GpSGHV infections by comparing the expression of three key RNAi machinery genes, Dicer $(D C R)$, Argonaute $(A G O)$ and Drosha, in artificially virus injected, asymptomatic and symptomatic infected G. pallidipes flies compared to PBS injected (controls) individuals. We further assessed the impact of AGO2 knockdown on virus infection by RT-qPCR quantification of four selected GpSGHV genes, i.e. odv-e66, dnapol, maltodextrin glycosyltransferase (a tegument gene) and SGHV091 (a capsid gene).

Results: We show that in response to hemocoelic injections of GpSGHV into G. pallidipes flies, increased virus replication was accompanied by significant upregulation of the expression of three RNAi key genes; AGO1, AGO2 and DCR2, and a moderate increase in the expression of Drosha post injection compared to the PBS-injected controls. Furthermore, compared to asymptomatically infected individuals, symptomatic flies showed significant downregulation of AGO1, AGO2 and Drosha, but a moderate increase in the expression of DCR2. Compared to the controls, knockdown of AGO2 did not have a significant impact on virus infection in the flies as evidenced by unaltered transcript levels of the selected GpSGHV genes.

Conclusion: The upregulation of the expression of the RNAi genes implicate involvement of this machinery in controlling GpSGHV infections and the establishment of symptomatic GpSGHV infections in Glossina. These findings provide a strategic foundation to understand GpSGHV infections and to control latent (asymptomatic) infections in Glossina spp. and thereby control SGHVs in insect production facilities.
\end{abstract}

Keywords: GpSGHV, RNAi, Sterile insect technique, Glossinidae, Tsetse, Symptomatic and asymptomatic infection, Covert infections

\footnotetext{
* Correspondence: a.m.m.abd-alla@iaea.org

${ }^{1}$ Insect Pest Control Laboratory, Joint FAO/IAEA Programme of Nuclear

Techniques in Food and Agriculture, International Atomic Energy Agency,

Vienna International Centre, P.O. Box 100, 1400 Vienna, Austria

Full list of author information is available at the end of the article
}

() International Atomic Energy Agency; licensee BioMed Central Ltd. 2018 This is an open access article distributed under the terms of the Creative Commons Attribution IGO License (https://creativecommons.org/licenses/by/3.0/igo/) which permits unrestricted use, distribution, and reproduction in any medium, provided appropriate credit to the original author(s) and the source is given. 


\section{Background}

Tsetse flies (Diptera: Glossinidae) are naturally infected by the Glossina pallidipes salivary gland hypertrophy virus (GpSGHV, family Hytrosaviridae), a large doublestranded DNA (dsDNA) virus pathogenic specifically to Glossina spp., [1, 2]. In G. pallidipes, although the majority of cultured and wild tsetse fly species are asymptomatically infected by GpSGHV (low virus titers), some unknown factors can trigger symptomatic infections (high virus titers) [3]. This, in turn, is associated with the occurrence of overt salivary gland hypertrophy (SGH) symptoms $[4,5]$. In the mass rearing of G. pallidipes, SGH epizootics reduce fly survival and productivity, and have caused the collapse of three colonies; two in the Insect Pest Control Laboratory (IPCL) in Seibersdorf, Austria (in 1987 and 2001), and one in the mass rearing facility in Kality, Ethiopia (in 2012) [6]. These GpSGHV-induced effects have significantly compromised the implementation of the sterile insect technique (SIT), a component of area-wide integrated pest management (AW-IPM) strategies designed for the eradication of G. pallidipes from the Southern Rift Valley of Ethiopia [7].

Although it is uncertain how the virus is maintained within tsetse populations in nature and in laboratory colonies, three hypothetical scenarios may account for the maintenance of asymptomatic GpSGHV infection state. The first is a persistent infection whereby the virus remains in specific host cells with low-level production of virions, but without causing substantial cell damage [8]. The second is a latent infection state, during which viral genomes and maybe some viral proteins are present in the infected host cells of certain organs, but without detectable production of infectious viral particles [9]. In the third, the virus can exist in both persistent and latent infection states at the same time, but in different tissues [9]. Persistent infection in the salivary gland (SG) cells is accompanied by a low number of virions $\left(10^{2}\right.$ viral genome copies/fly) released by asymptomatic flies via saliva during feeding [10]. In addition, detection of viral DNA in other tissues such as the tracheal cells without detectable viral gene transcripts [11] may reflect a latent infection state. In any case, the persistent or latent GpSGHV infection in G. pallidipes potentially represents a homeostatic equilibrium between the host's immune system and the viral escape strategies. Consequently, the viral infection is kept under control (asymptomatic state), but is not completely eliminated from the fly.

Amongst the possible host mechanisms that keep GpSGHV under control is the insect's RNA interference (RNAi) machinery, which regulates both host and viral gene expression by use of small RNAs that bind to their complementary messenger RNA (mRNA) targets [12, 13]. This hypothesis is based on evidence from various studies indicating that the RNAi machinery is a conserved antiviral defense mechanism for several groups of large dsDNA viruses infecting insects, including the related baculoviruses and nudiviruses, as well as ascoviruses and iridoviruses [14, 15]. RNAi is mediated through three pathways: short interfering RNA (siRNA), microRNA (miRNA) and Piwi-interacting RNA (piRNA) pathways [16]. The siRNAs are processed in the cytoplasm by the ribonuclease III enzyme Dicer-2 (DCR2) from exogenous double stranded (ds) RNAs (e.g. dsRNAs that arise as viral replication intermediates or from overlapping transcripts). These siRNAs destroy (viral or cellular) single-stranded RNAs (ssRNAs) in a sequence-specific manner [17]. The miRNAs, on the other hand, are processed by DCR1 from cellular or viral pre-miRNAs, originating from DNA components of nuclear replicating viruses that are processed by RNase III enzyme Drosha in the nucleus [18]. The miRNAs are then exported to the cytoplasm where they posttranscriptionally regulate cellular or viral protein expression, thereby modulating developmental and physiological processes of the host as well as virus infection $[19,20]$. The piRNAs are processed via diverse pathways independent of DCR proteins [21], and are involved in the regulation of cellular genes and activities of transposons [22]. They may also have a role in antiviral strategies, as has been suggested for arboviruses [23]. In the RNAi biogenesis pathways, the siRNAs, miRNAs and piRNAs are loaded into Argonaute proteins 2, 1 and 3 (AGO2, 1 and 3), respectively, that mediate the RNAi by either cleavage or degradation of target RNAs (AGO2), translation repression (AGO1), or epigenetic modifications (AGO3) [24]. However, some of the abovementioned enzymes may participate in two or more of these pathways. For instance, in Drosophila melanogaster, DCR1 is involved in both siRNA and miRNA pathways, while DCR2 is only involved in the siRNA pathway. Additionally, Drosophila AGO1 and AGO2 enzymes may participate in both the siRNA and miRNA pathways [25].

The siRNA-mediated RNAi pathway is a potent antiviral immune pathway in insects [21,26] and is implicated in controlling the replication of RNA and DNA viruses [15, 27-30]. In addition, it has been shown for several viruses that the knockdown of RNAi pathway components leads to increased viral replication. For instance, loss-offunction mutations in DCR2 enhanced the susceptibility of Helicoverpa armigera to infection by $H$. armigera single nucleopolyhedrovirus (HearNPV) [28]. Similar observations were made in Drosophila during infection by Flock House virus (FHV), Drosophila C virus (DCV), and Sindbis virus (SINV) [31]. In addition to controlling viral replication, the siRNA pathways have also been implicated in establishing persistent virus infection [32]. To establish 
persistent infection, viral fragments generated during viral DNA genome replication are transcribed or reverse transcribed for RNA viruses and integrated into the host genome. The generated transcripts are processed by DCR2 into virus-derived siRNAs (vsiRNAs); the vsiRNAs are then loaded into AGO2 to mediate specific cleavage of viral mRNAs, leading to persistent infection [32-34]. In the case of GpSGHV infections, the outcome of RNAibased immune responses would hypothetically be restriction of viral replication and prevention of the development of overt SGH. If this is indeed the case, then virus and host would progress into a stable equilibrium of a persistent or latent infection state, which may account for the widespread chronic asymptomatic GpSGHV infections in many tsetse species, particularly in colonized flies [10].

In the current study, we evaluated whether GpSGHV infection induces an RNAi response in G. pallidipes and whether this would downregulate the development of SGH and instead induce a covert infection state (persistent or latent). To accomplish this, we performed comparative analyses of the expression of $A G O, D C R$ and Drosha between artificially (intra-hemocoelic) virus injected and uninfected (PBS injected) individuals, and between asymptomatic and symptomatic infected flies (with overt SGH symptoms). It should be noted that artificial injection of the virus does not result into overt SGH in the same (parental) generations but in the progeny flies [35]. We complemented these bioassays by testing the impact of downregulation of a key component in the siRNA pathway (AGO2), on GpSGHV infection in G. pallidipes. The data obtained in this study offer a rationale for similar studies on other Hytrosaviridae family members and may open novel strategies to manage SGHVs in insect production facilities.

\section{Results}

\section{The Argonaute family in Glossina species}

The analyses of the genomes of G. pallidipes, G. m. morsitans, G. f. fuscipes, G. p. palpalis, G. austeni and G. brevipalpis resulted in the identification of AGO 1, 2 and 3 in all these species (See Table 1), key components of the RNA induced silencing complex (RISC); AGOs activate and cleave target mRNA within the RISC complex [36]. The identification of AGOs in the six tsetse species underscores the conservation of the RNAi machinery in Glossina species. Phylogenetically, the three AGO proteins segregated into distinct clusters with their orthologs in D. melanogaster, which corresponded to the siRNA, microRNA and piRNA pathways of the RNAi machinery (Fig. 1a). The phylogenetic clustering was supported by robust bootstrap values. Additionally, similar to the D. melanogaster AGO family proteins, their orthologs in Glossina species contained the critical functional domains, i.e. the PAZ domain (for dsRNA binding) and the PIWI domain (executioner of the RNase activity) (Fig. 1b). These results strongly suggest that the three RNAi machinery pathways are functional in Glossina spp.

\section{The dicer family in Glossina species}

The bioinformatics analysis of the DCR protein family did not result in the identification of the homolog to the Drosophila DCR1 protein in G. pallidipes and G. brevipalpis, but the other Glossina species included in this study contained a DCR1 protein homolog (Fig. 2a). However, homologs to the Drosophila DCR2 protein were present in both G. pallidipes and G. brevipalpis, suggesting that DCR2 might be involved in both siRNA and miRNA pathways, at least in these species. However, DCR2 was lacking in G. p. palpalis and G. austeni (Fig. 2a), implying that in these two species DCR1 might be involved in both siRNA and miRNA pathways. Homologs to both DCR1 and DCR2 were found only in G. m. morsitans and G. f. fuscipes suggesting that in these species they may be involved in two separate pathways (e.g. miRNA and siRNA) as reported in Drosophila [37]. Drosha was present in all six tsetse species investigated (Fig. 2a). Our bioinformatics analysis revealed the presence of all the functional motifs in the identified DCR (N-terminal helicases, DCR- dsRBF, PAZ, two C-terminal RNA III, and dsRBD) and Drosha (C-terminal RNA III and the dsRBD) protein homologs, which were organized as in their orthologs in $D$.

Table 1 Accession numbers of Argonaute, Dicer and Drosha genes of Glossina species and D. melanogaster found in the VectorBase database

\begin{tabular}{lllllll}
\hline Species & Argonaute 1 & Argonaute 2 & Argonaute 3 & Dicer 1 & Dicer 2 & Drosha \\
\hline G. pallidipes & GPAI022202-RA & GPAl002659-RA & GPAI022224-RA & - & GPAI041589-RA & GPAI009042-RA \\
G. m. morsitans & GMOY010338-RA & GMOY004940-RA & GMOY010351-RA & GMOY008446-RA & GMOY001890-RA & GMOY008669-RA \\
G. fuscipes & GFU1031750-RA & GFUI006141-RA & GFUI039869-RA & GFUI018989-RA & GFUI024311-RA & GFUI012078-RA \\
G. palpalis & GPPI043499-RA & GPPI035929-RA & GPPI041119-RA & GPPI007107-RA & - & GPPI000118-RA \\
G. austeni & GAUT002476-RA & GAUT035389-RA & GAUT027143-RA & GAUT008865-RA & - & GAUT013637-RA \\
G. brevipalpis & GBRI043708-RA & GBRI017817-RA & GBRI017128-RA & - & GBRI010244-RA & GBRI016708-RA \\
D. melanogaster & NM_166020.2 & NM_140518.3 & NM_001043162.3 & NM_079729.3 & NM_079054.5 & NM_058088.4 \\
\hline
\end{tabular}



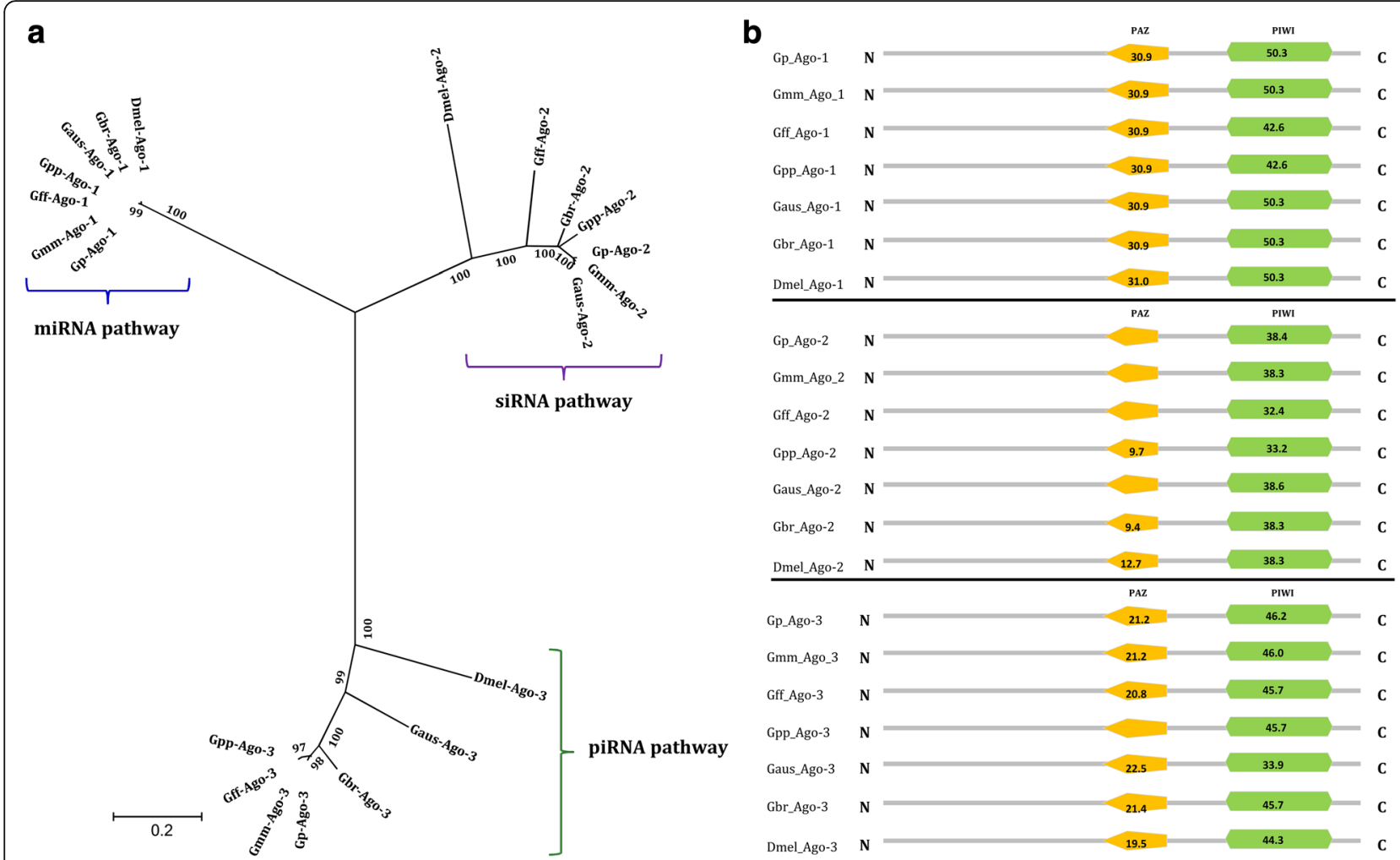

Fig. 1 Phylogenetic and domain analysis of Argonaute proteins. a Maximum-likelihood based phylogenetic analysis (1000 bootstrap replicates) of Argonaute amino acid sequences of six tsetse species based on full length alignment with D. melanogaster as an outgroup. $\mathbf{b}$ Domain architecture of Argonaute proteins. The numbers on the domains are the scores produced by the ScanProsite search compared to the PROSITE protein domain database. All the tsetse $\mathrm{AGO1}, \mathrm{AGO}$, and $\mathrm{AGO} 3$ proteins show similarity in the domain architecture to their orthologs in $D$. melanogaster (Dmel-AGO1, Dmel-AGO2 and Dmel-AGO3), respectively. Abbreviations; AGO (Argonaute), Gp (G. pallidipes), Gmm (G. m. morsitans), Gff (G. f. fuscipes), Gbr (G. brevipalpis), Gpp (G.p. palpalis), Gaus (G. austeni) and Dmel (D. melanogaster)

melanogaster (Fig. 2b). Notably, no major differences (phylogenetic and domain architecture) were observed between the DCR1 or DCR2 protein sequences of the tsetse species containing one or both DCR proteins (Fig. 2a and b). The presence of the functional domains in DCR and Drosha homologs could imply the conservation and functionality of both siRNA and miRNA pathways in tsetse. As indicated above, the piRNA pathway is independent of DCR implying that function of this pathway may not be affected by the presence or function of this protein.

\section{Expression levels of $A G O, D C R$ and Drosha in virus-injected G. pallidipes}

Having identified the core genes involved in the RNAi machinery pathways, we determined whether GpSGHV infection induces an RNAi response. Using G. pallidipes as the model species, and due to the absence of $D C R 1$ in this Glossina species (See Fig. 2), we quantified the expression levels of the $A G O$ family ( $A G O 1$, $A G O 2$ and $A G O 3), D C R 2$, and Drosha in flies injected with the virus suspensions compared to the PBS-injected control flies. Additionally, we correlated the expression levels of these RNAi-related genes to the level of virus replication by quantifying the expression levels of GpSGHV $o d v-e 66$, a conserved and late viral gene. Compared to the control (PBS-injected) fly group, the expression of odv-e66 increased significantly with time $(t=8.657$; d.f. $=44 ; P<$ 0.001) (Fig. 3a), implying active replication and late gene expression of the virus in the injected flies. This increased virus replication was accompanied by a significant increase in the expression level of AGO1 $(t=2.306$; d.f. $=44 ; P=0.026)$ and $A G O 2(t=3.334$; d.f. $=44 ; P$ $=0.00174)$ but not $A G O 3(t=1.651$; d.f. $=44 ; P=$ 0.106), of which the AGO2 (involved in siRNA pathway) was the most upregulated (compare panels $\mathrm{B}, \mathrm{C}$ and D in Fig. 3). Similarly, to the AGO genes DCR2, which may be involved in both siRNA and miRNA pathways in G. pallidipes, was also found to be significantly upregulated $(t=3.968$; d.f. $=44 ; \mathrm{P}<0.001)$ in response to the virus injection (Fig. 3e). However, unlike $A G O$ and $D C R$, the expression levels of Drosha showed no significant increase $(t=0.601$; d.f. $=44 ; P$ $=0.551)$ in the virus-injected flies compared to the 

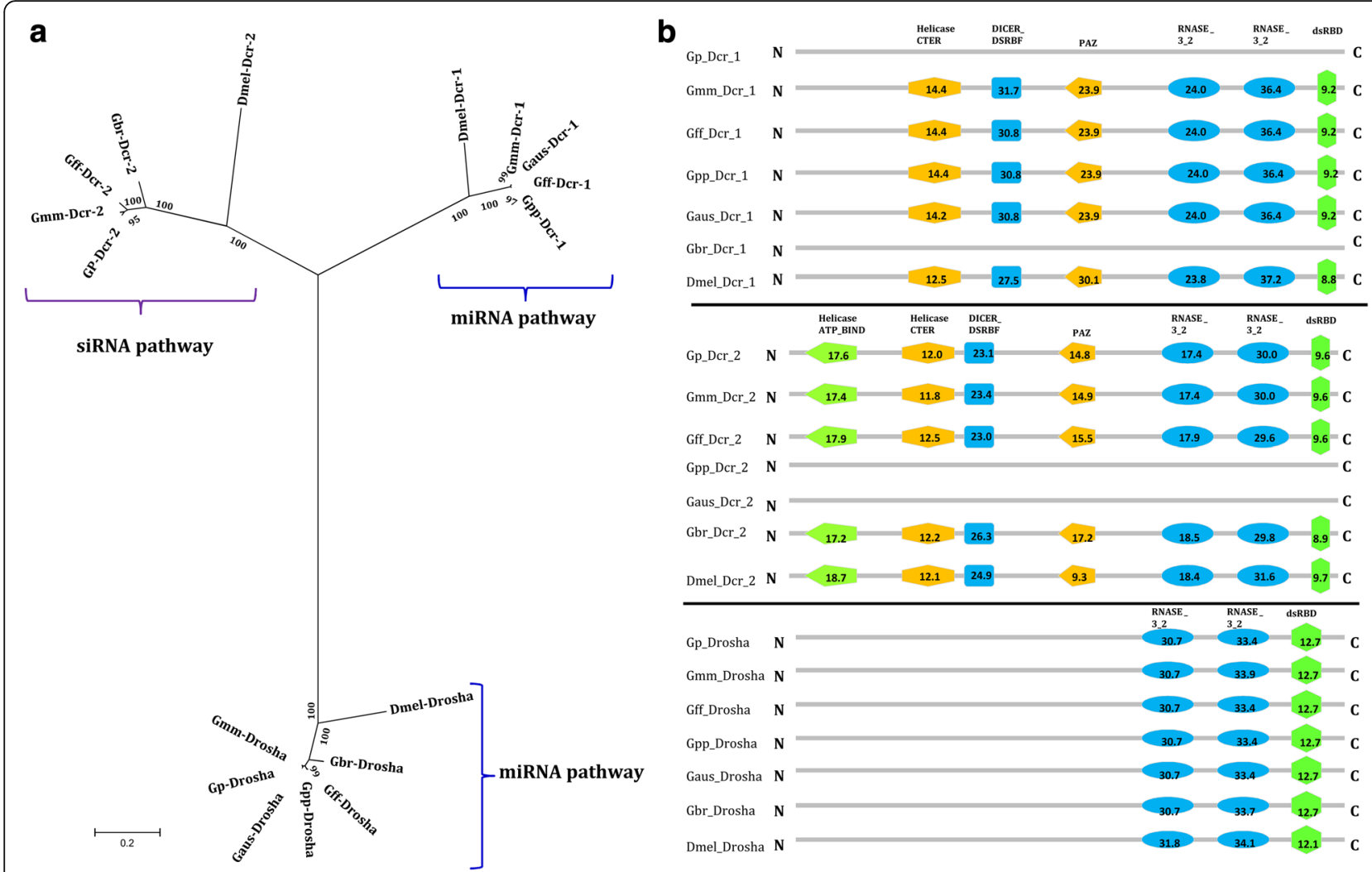

Fig. 2 Phylogenetic and domain analysis of Dicer and Drosha proteins. a Maximum-likelihood based phylogenetic analysis (1000 bootstrap replicates) of Dicer and Drosha amino acid sequences of six tsetse species based on full length alignment with $D$. melanogaster orthologs as outgroup. b Domain architecture of Dicer and Drosha proteins. Some of the tsetse species had either DCR1 or DCR2 proteins, but Drosha was found in all the species. The numbers on the domains are the scores produced by the ScanProsite search compared to the PROSITE protein domain database. All DCR1, DCR2 and Drosha proteins show similarity in the domain architectures to Dmel-DCR1, Dmel-DCR2 and Dmel-Drosha, respectively. Abbreviations; DCR (Dicer), Gp (G. pallidipes), Gmm (G. m. morsitans), Gff (G. f. fuscipes), Gbr (G. brevipalpis), Gpp (G. p. palpalis), Gaus (G. austeni) and Dmel (D. melanogaster)

levels observed in the PBS-injected flies (Fig. 3f). This suggests that Drosha, part of the miRNA pathway, is not involved in the immune response against a lytic infection by GpSGHV. Full statistics for each regression are given in Additional file 1.

\section{Expression levels of $A G O, D C R$ and Drosha in symptomatic G. pallidipes}

We also compared the expression levels of the $D C R$ and $A G O$ family genes in the virus-injected G. pallidipes flies described above with the expression levels in symptomatic (flies with overt SGH symptoms and high virus titers) and asymptomatically infected individuals (flies with low virus titers) $(t=16.72$; d.f. $=10 ; P<0.001)$ (Fig. 4a). We found that $A G O 1(t=-5.454$; d.f. $=10 ; P<0.001)$, AGO2 $(t=-3.899 ;$ d.f. $=10 ; P=0.00363)$ and Drosha $(t=-3.549$; d.f. $=10 ; P=0.00623)$ were significantly downregulated in symptomatic G. pallidipes flies as compared to asymptomatically infected flies (Fig. 4b). There was no difference in $D C R 2(t=1.318$; d.f. $=10$;
$P=0.2202)$, or $A G O 3(t=-0.858$; d.f. $=10 ; P=0.413)$ expression between the asymptomatic and symptomatic infected flies (Fig. 4b).

Effect of $A G O 2$ knockdown on virus infection in G. pallidipes We also assessed the impact of $A G O 2$ knockdown on GpSGHV infection. The $A G O 2$ gene, which is involved in the siRNA pathway, was chosen for knockdown largely because its expression levels were significantly modulated in both the virus-injected flies (upregulated; see Fig. 3c) and symptomatic infected flies (downregulated; See Fig. 4b). Notably, compared to the flies injected with nuclease-free water, injection of flies with the dsRNAs did not cause any difference in mortality rate. The injection of dsRNAs specific for $A G O 2$ and tsetse EP in addition to PBS or virus injection resulted in a significant decrease in the expression levels of both $A G O 2$ (AGO2dsRNA/PBS cf. water/PBS: $t=$ - 4.265; d.f. $=42 ; P<0.001, \mathrm{AGO} 2 \mathrm{dsRNA} /$ virus cf. water $/$ virus: $t=-3.543$ d.f. $=42 ; \mathrm{P}<0.001$ ) (Fig. $5 \mathrm{a}$ ) and tsetse $E P$ (TsetseEPdsRNA/PBS cf. water/PBS: $t=-5.392$; d.f. $=40$; 


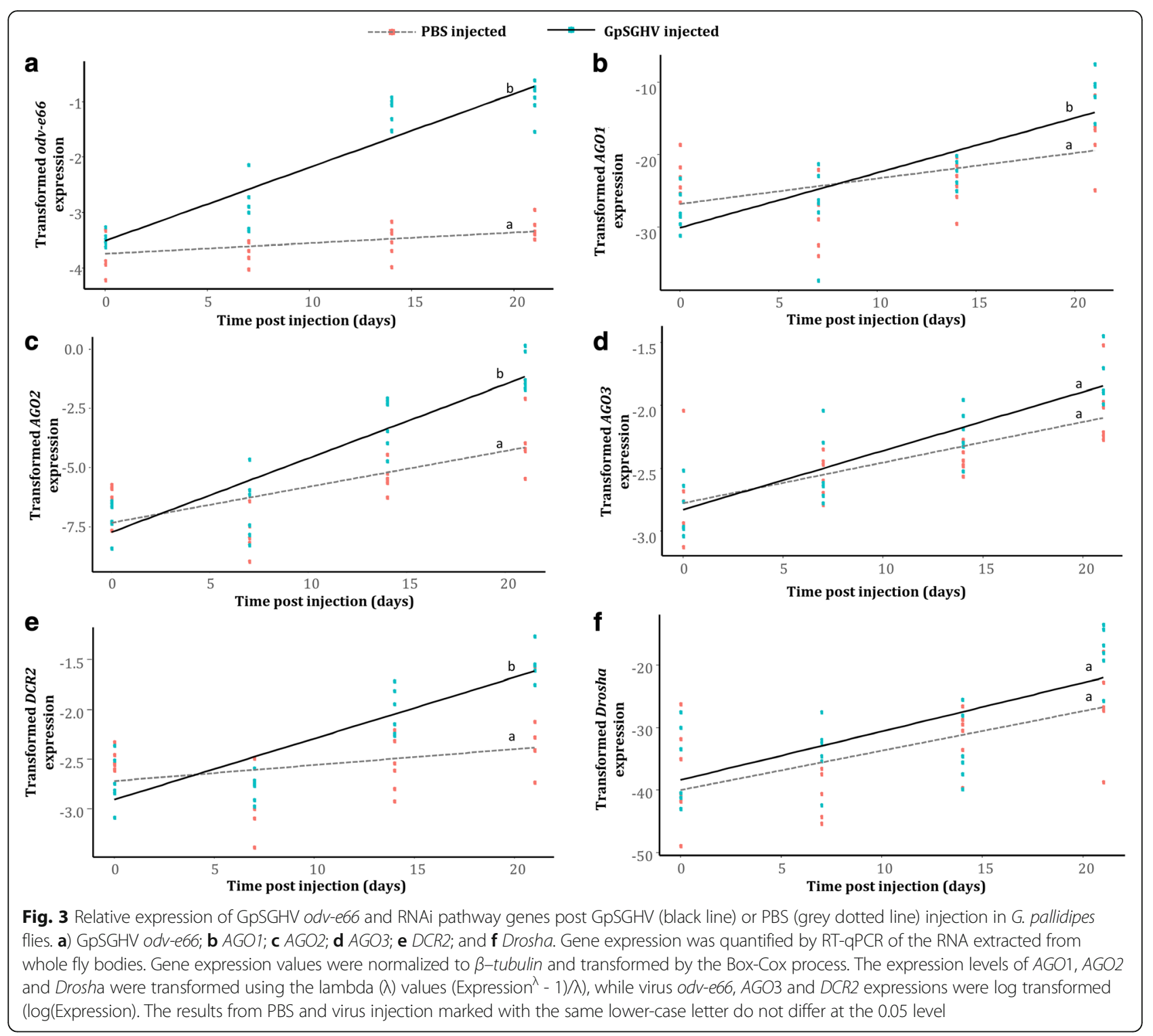

$\mathrm{P}<0.001$, TsetseEPdsRNA/virus cf. water/virus: $t=-6.798$; d.f. $=40 ; \mathrm{P}<0.001$ ) (Fig. 5b), respectively, compared to the water-injected control flies. We then assessed the effect of AGO2 knockdown on virus infection by quantifying expression levels of the selected viral genes, odv-e66, DNApol, SGHV038 and SGHV091. AGO2 knockdown did not have a significant impact on the transcript levels of any of the selected viral genes; odv-e66 $(t=-1.861$; d.f. $=119 ; P=$ 0.391), DNApol $(t=-0.422 ; \quad$ d.f. $=119 ; \quad P=0.674)$, SGHV038 $(t=-0.179$; d.f. $=119 ; P=0.858)$ and SGHV091 $(t=-0.877$; d.f. $=119 ; P=0.382)$ compared to the controls (Fig. 6a, b, c and d). As expected, knockdown of tsetse EP, which is not associated with the RNAi machinery, did not affect the expression levels of these selected viral genes. The transformations and parameters for all regression analyses are given in Additional file 1.

\section{Discussion}

In the current study, we have investigated the potential involvement of the RNAi machinery during GpSGHV infections in G. pallidipes by quantifying the expression of both the host ( $A G O, D C R$ and Drosha) and four viral genes. The finding that AGO and DCR proteins in Glossina species contain the functional domains or motifs known to mediate the RNAi response strongly indicate that the RNAi machinery is functional in tsetse, presumably in a similar version as reported in Drosophila [38]. It is known that the presence or absence of these functional domains in AGO or DCR proteins affects the efficiency of the RNAi response. For instance, $\mathrm{Gu}$ et al. [39] discovered that although AGO2 lacking the PAZ domain interacts with duplex siRNAs, the truncated protein was unable to unwind the siRNAs or eject the passenger 


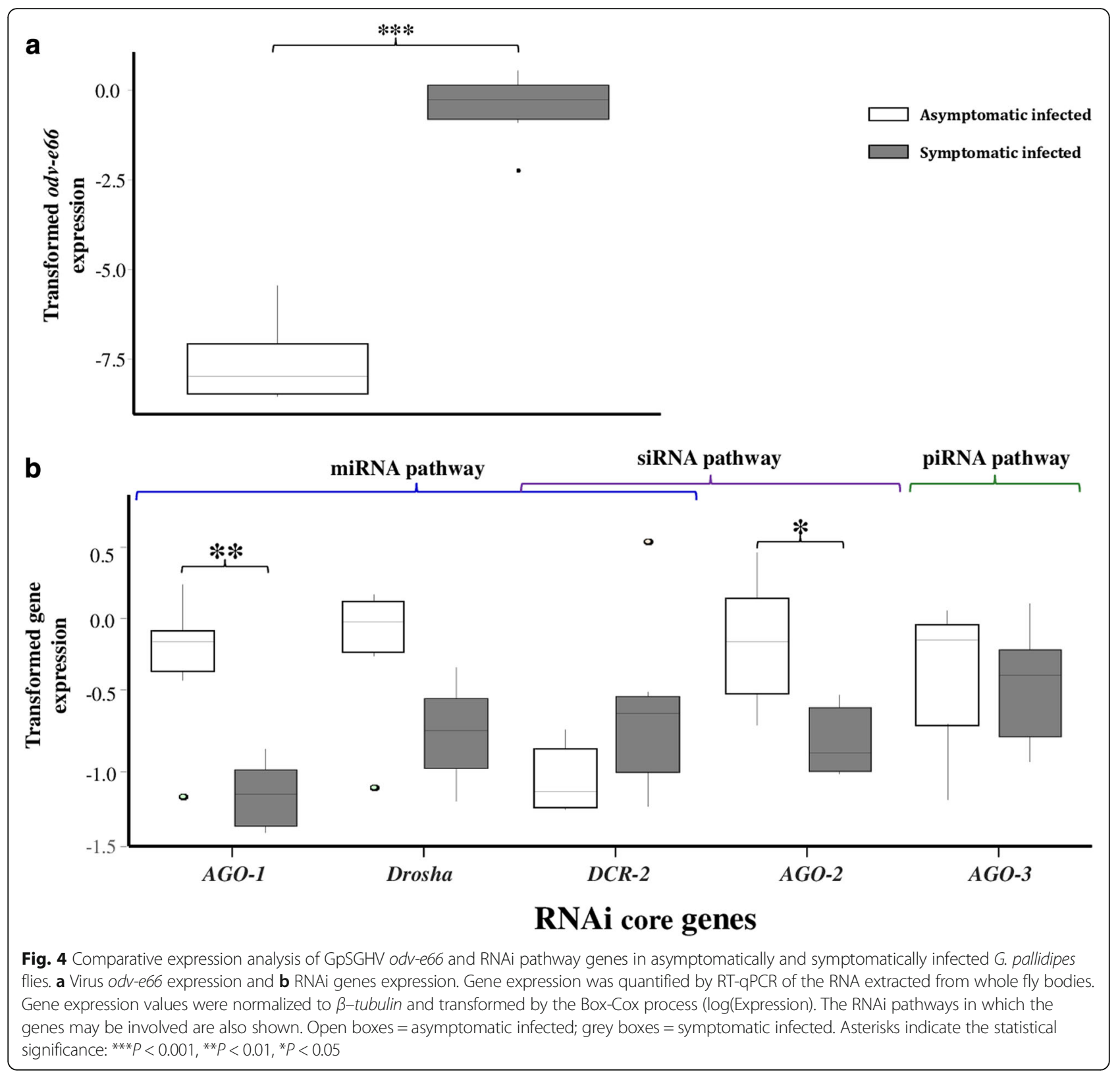

RNA strands. The passenger strand should be degraded or ejected from the siRNA duplex to allow the guide strand to be incorporated into the RISC complex and target the mRNA [21]. Moreover, the results from our phylogenetic analysis confirmed that the predicted AGO proteins from the various tsetse species analyzed clustered with those of Drosophila.

The presence of only DCR2 in G. pallidipes and G. brevipalpis, and only DCR1 in G. p. palpalis and G. austeni suggest that in these species only one of the respective proteins is involved in the siRNA and miRNA pathways. In contrast, genes for both DCR1 and DCR2 proteins were found in G. m. morsitans and G. f. fuscipes. Given that in Drosophila DCR1 and DCR2 are involved in the miRNA and siRNA pathways, respectively [37], it is possible that these two proteins are involved in these pathways in these two Glossina species as well. Alternatively, they might be involved in both pathways, as suggested for the other Glossina species as there were no differences in DCR1 or DCR2 protein sequences of species with one or both DCR proteins, which could be linked to the RNAi pathways. The DCR proteins can be involved in both siRNA and miRNA pathways [24] or be involved in the separate pathways [37]. Taken together, the identification of genes for AGO and DCR proteins may, in principle, be an indication of a robust RNAi silencing response in Glossina species $[40,41]$. 


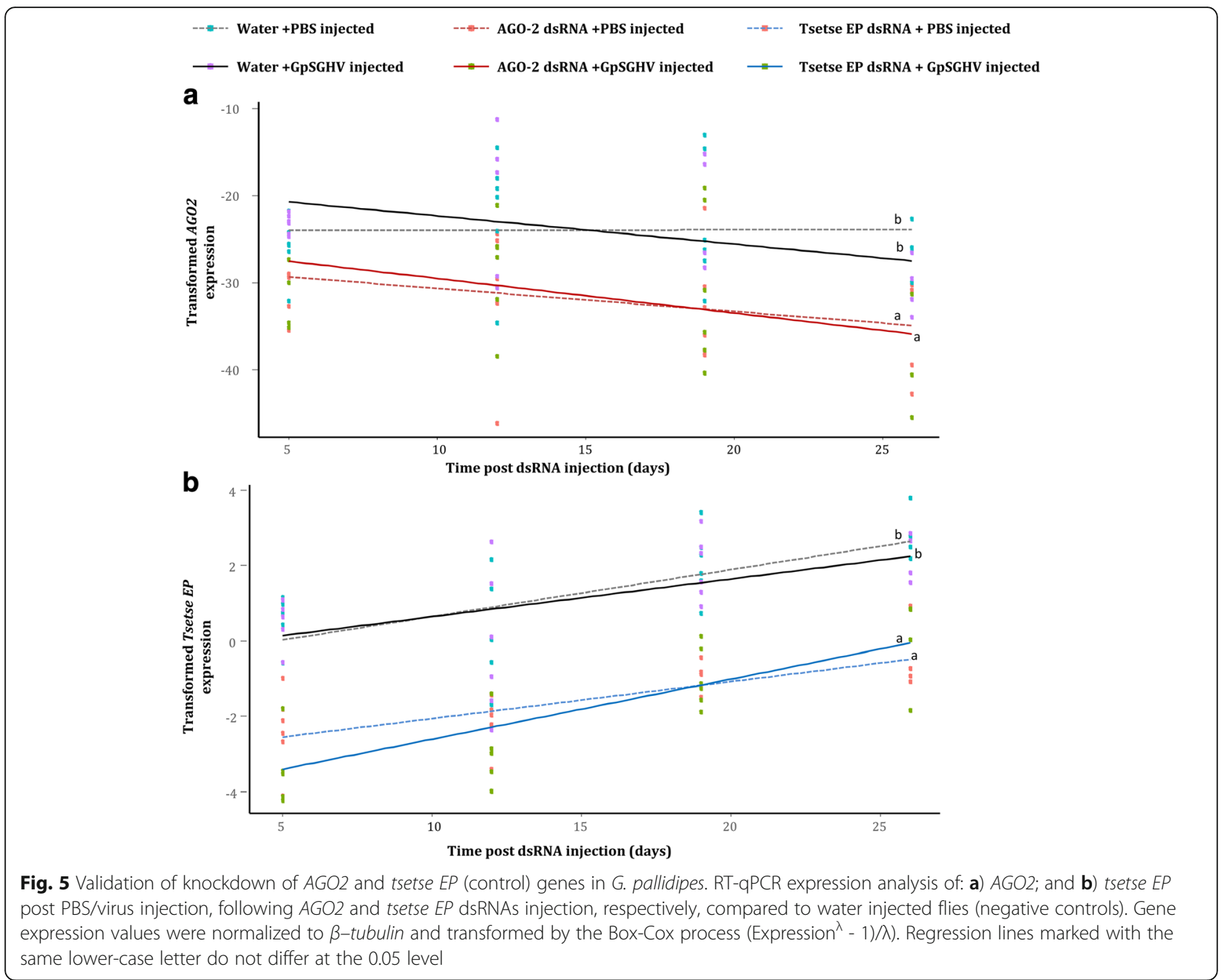

Currently, the mechanism(s) permitting the covert (asymptomatic) GpSGHV infection in G. pallidipes, and the reactivation from viral persistence/latency to overt symptomatic infection that is associated with overt SGH symptoms [35], are poorly understood. Our finding of significant upregulation of the expression of $A G O 2$ in GpSGHV-injected flies suggests that the virus infection induces the host's siRNA-mediated response, presumably to inhibit the virus infection. Notably $D C R 2$, which might be involved in both siRNA and miRNA pathways in G. pallidipes, was similarly upregulated during virus infection. The upregulated expression of both AGO2 and DCR2 post virus injection in G. pallidipes, which are key components in the dsRNA-mediated gene silencing in several insects, suggests a functional RNAimediated innate immunity response in Glossina species. However, more work is required to elucidate the precise details of this pathway in Glossina as well as the involvement of the RNAi machinery in other members of the Hytrosaviridae family.
In contrast to the above-mentioned increased levels of $A G O 2$ and $D C R 2$ in virus-injected flies, the comparative analysis of the expression of the two genes between asymptomatic and symptomatic infections showed a significant downregulation of the expression of AGO2, but insignificant upregulation of $D C R 2$ in the flies exhibiting diagnostic SGH symptoms. The high expression of siRNA pathway genes in the virus-injected flies suggests a tight control of the virus via the RNAi response during asymptomatic GpSGHV infections. However, during symptomatic infections as evidenced by increased virus titers, the siRNA pathway may be compromised (as supported by the low expression of $A G O 2$ ) enabling the virus to escape the RNAi-mediated innate immunity, thereby increasing virus titers and in turn causing the detectable SGH symptoms. A similar outcome has been documented in the case of the African malaria mosquito, Anopheles gambiae, where dsRNA-mediated silencing of $A G O 2$, which functions in conjunction with $D C R 2$ in this mosquito, resulted in increased O'nyong- 


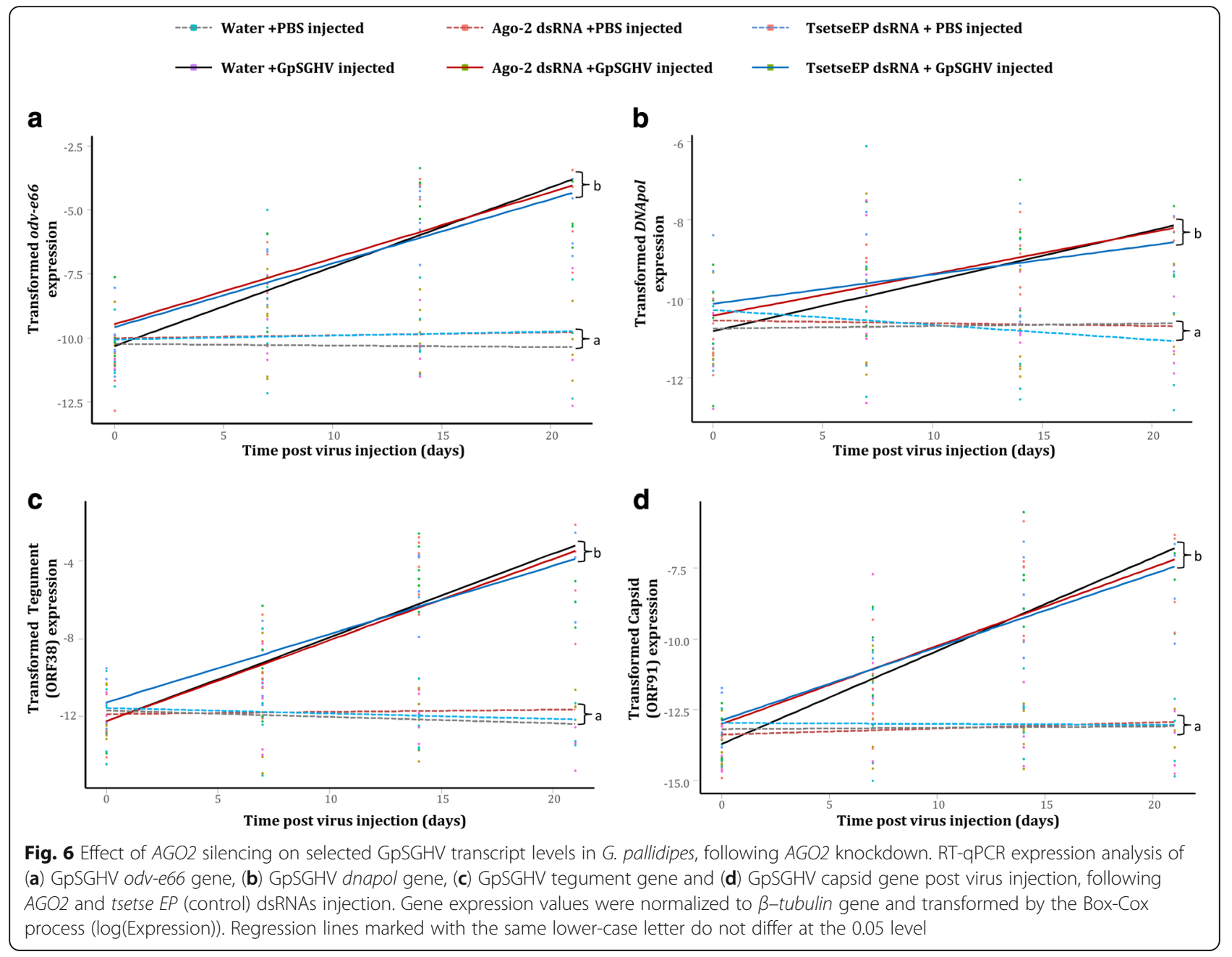

nyong virus (ONNV) viral loads [42]. It should be noted that, due to its involvement in both the siRNA and miRNA pathways, DCR2 was not considered a suitable candidate for the knockdown assays in this study. Therefore, we assessed the potential involvement of dsRNA-mediated gene silencing (siRNA pathway) in G. pallidipes by knockdown of AGO2.

Several examples of the function of RNAi in insects have been clearly demonstrated, including for species from the orders Diptera, Dictyoptera, Isoptera, Hymenoptera and Orthoptera $[43,44]$. In the case of tsetse flies, Walshe et al., [45] showed that micro-injection of dsRNA into 68 day-old G. $m$. morsitans flies could persistently silence expression of tsetse EP, a gene that is demonstrated to protect the fly against establishment of trypanosome infections in the midgut [46]. In the current study, the knockdown of AGO2 in G. pallidipes did not alter the transcript levels of the selected GpSGHV genes implying that AGO2 knockdown had no effect on the GpSGHV infection. These findings are in contrast to previous results; for instance in Drosophila melanogaster in which flies that were deficient in the DCR2 protein showed increased susceptibility to infection by members of three different RNA virus families; i.e. FHV (Nodaviridae), DCV (Dicistroviridae), and SINV (Togaviridae) [31]. In general, many studies have led to the conclusion that flies that contain mutations in genes that encode components of the siRNA pathway (including DCR2 and AGO2) or the Janus kinase/ signal transducers and activators of transcription (JAK-STAT) pathway, are not only more sensitive to infection by several viruses, but also harbor higher viral titers than their wild-type counterparts. The JAK-STAT pathway is also a conserved insect innate immune antiviral response [13, 26, 31, 38, 47]. In another report, $D$. melanogaster defective for the AGO2 were found to be hypersensitive to infections by $\mathrm{DCV}$, an infection which also supported a 1000-fold increased production of progeny virus [47].

The results obtained from the current study showed that reduction of RNAi efficiency in G. pallidipes did not cause a significant impact on the fly immunocompetence. Notably, in addition to the RNAi pathway 
investigated in this study, the JAK-STAT, immune deficiency (imd) and Toll immune pathways are also involved in elimination of viruses [48-50]. The presence of these innate immune pathways may indicate that following the interruption of the RNAi pathway in G. pallidipes flies in our study alternative antiviral pathways in these flies were able to control the virus infections.

\section{Conclusions}

Given the high diversity of pathogens, their elimination by host organisms is challenging and therefore many organisms, including insects, employ multiple mechanisms to deal with them. The RNAi machinery, particularly the siRNA pathway, plays a central role in insects by specifically recognizing and eliminating invading pathogens and other invasive elements such as transposons. This study has elucidated important milestones in the infection of GpSGHV in Glossina spp. We detected RNAi key genes in all the analyzed Glossina species, which may indicate a functional antiviral role of RNAi machinery in tsetse flies. In G. pallidipes, the model Glossina species in this study, the siRNA pathway genes AGO2 and DCR2 were upregulated during virus infection, which confirmed the involvement of the RNAi response in the flies' defense against GpSGHV. We also noted that in G. pallidipes, the siRNA pathway was compromised during symptomatic infection as evidenced by the low expression of AGO2. However, although knockdown of AGO2 in G. pallidipes did not have an impact on virus infection, it would be worthwhile to further investigate the long-term effects of the gene knockdowns on GpSGHV transmission and the expression of SGH symptoms in $F_{1}$ progeny produced by the parents with the knockdown. The $F_{1}$ generation is of interest since induction of SGH symptoms does not occur in the parental generation of flies that are intra-hemocoelically injected with the virus but are observed in the subsequent $F_{1}$ generation produced by injected mothers [35]. It may therefore be important to determine whether the dsRNA-mediated gene silencing is a heritable trait, as has been demonstrated in other studies [51]. The next question would be to determine which factors (exogenous or endogenous) trigger the transition from the asymptomatic to symptomatic state in colonized and wild flies. Together, the approach and results of the current study offer a starting point for further investigations into Hytrosaviridae family members and may open novel strategies to control SGHVs in insect production facilities.

\section{Methods}

\section{Tsetse fly and virus injections}

The G. pallidipes flies used in this study were obtained from the colony maintained at the Joint FAO/IAEA
IPCL, Seibersdorf, Austria. G pallidipes was selected for this study because, unlike other species, it shows both asymptomatic and symptomatic virus infections [3]. The experimental G. pallidipes flies were maintained in controlled insectaria with $70-80 \%$ relative humidity, $24 \pm 1{ }^{\circ} \mathrm{C}$ temperature and $12 \mathrm{~h}$ photo-phase. The flies were fed for 10-15 min, 3 times per week on defibrinated bovine blood using an in vitro membrane feeding system [52]. The virus inoculum was prepared from a one pair of hypertrophied salivary glands (with overt SGH symptoms) dissected from G. pallidipes male flies; viral titers in the gland homogenates (in PBS) were estimated by qPCR as described previously $[3,35]$. The experimental flies were injected with $2 \mu \mathrm{l}$ of the virus inoculum estimated to contain $\sim 10^{6}$ virus genome copies per $\mu \mathrm{l}$.

\section{Identification of core RNAi gene orthologs in Glossina}

To determine whether the G. pallidipes genome contains the key RNAi pathway genes, $A G O, D C R$ and Drosha sequences were retrieved from the VectorBase database [53] using as query sequences the annotated homologous gene sequences of G. morsitans morsitans [54] (BLASTp; e-value $\leq 10^{-2}$ ). To determine the conservation of RNAi in Glossina species, sequences of these core genes for G. fuscipes fuscipes, G. palpalis palpalis, G. austeni and G. brevipalpis were similarly retrieved from VectorBase. The functional domain architecture of the retrieved $A G O, D C R$ and Drosha sequences was analyzed using the ScanProsite tool [55]. Homologous search of the retrieved sequences was performed to determine the relatedness of these sequences with those of D. melanogaster for which RNAi mechanisms and pathways have been demonstrated. Multiple alignments of protein-coding loci of the identified gene sequences were performed in BioEdit [56]. Phylogenetic analysis was performed with MEGA6 using default settings for MaximumLikelihood (ML) based on the General Time Reversible model with gamma distributed substitution rates with 1000 bootstrap replications [57].

\section{Analysis of the expression of core RNAi genes in virus- injected G. pallidipes by RT-qPCR}

To investigate the impact of GpSGHV on the core RNAi genes in G. pallidipes, two groups of teneral flies (newlyeclosed and non-fed; 50 females and 50 males per group) were injected with either the virus inoculum as described above, or phosphate buffered saline (PBS) as control. Following the injections, four females and four males were sampled within $1 \mathrm{~h}$ post injection and at 7,14 and 21 days post injection (dpi). Total RNA was extracted from individual whole bodies of the sampled flies using Trizol reagent (Invitrogen, Paisley UK) according to the 
manufacturer's instructions. Contaminating DNA was removed from the extracted RNA by treating the samples with DNase 1 (Invitrogen, Paisley, UK), after which the concentration of the RNA was quantified using a Nanodrop ND-1000 spectrophotometer (Thermo Fisher Scientific, Wilmington, DE). Complementary DNAs (cDNAs) were synthesised using the SuperScript ${ }^{\circ}$ III Reverse Transcriptase kit (Invitrogen, Paisley UK) following the manufacturer's instructions. The iQ SYBR green supermix (Bio-Rad laboratories, Hercules, CA) was used for RT-qPCR analysis. The viral infection was assessed by quantifying the expression of GpSGHV $o d v-e 66$, a conserved, late viral gene (highly expressed upon viral genome replication), followed by expression analysis of $A G O, D C R$ and Drosha transcripts, using the PCR cycling conditions: $95{ }^{\circ} \mathrm{C}$ for $3 \mathrm{~min}$, followed by forty cycles of $95{ }^{\circ} \mathrm{C}$ for $10 \mathrm{~s}, 60{ }^{\circ} \mathrm{C}$ for $1 \mathrm{~min}$, then $95{ }^{\circ} \mathrm{C}$ for $1 \mathrm{~min}$ and $55^{\circ} \mathrm{C}$ for $1 \mathrm{~min}$, using the primers shown in Table 2. The tsetse housekeeping gene $\beta$-tubulin was used to normalize gene expression.
Differential expression of RNAi genes in asymptomatic and symptomatic flies

To determine the differential expression of $A G O, D C R$ and Drosha between asymptomatic and symptomatic infected flies, 10-day old $F_{1}$ progeny flies produced by virus injected mothers were screened under a stereo microscope for the occurence of diagnostic SGH symptoms. Total RNA was extracted from whole bodies of 8 asymptomatic and 8 symptomatic infected flies (4 females and 4 males). The viral infection was estimated by quantification of the GpSGHV odv-e66 transcripts, followed by expression analysis of the three genes as described above. These expression analyses were replicated three times (biological replicates).

Design of dsRNA constructs and prediction of off-targets The optimal regions on the AGO2 mRNA for the synthesis of dsRNA constructs were determined by siRNA design software (default setting) [58], which uses three predictive steps; (i) selection of functional siRNA

Table 2 Sequences of the primers used in synthesis of dsRNAs and for expression analysis by RT-qPCR

\begin{tabular}{|c|c|c|c|}
\hline Target gene & Primer name & Primer sequence (nt) - Primers are listed $5^{\prime}-$ to $-3^{\prime}$ & Reference \\
\hline \multicolumn{4}{|l|}{ A Primers for dsRNAs synthesis } \\
\hline \multirow[t]{2}{*}{ Argonaute 2} & AGO-2 T7-F & TAATACGACTCACTATAGGGGTCTTAGCATCCAACAACCA & This study \\
\hline & AGO-2 T7-R & TAATACGACTCACTATAGGGTGTCTATGCCGCACTCTITC & \\
\hline \multirow[t]{2}{*}{ Tsetse EP } & TseEPT7-F & TAATACGACTCACTATAGGGCTACGATAAATATGTCCCTCTAAT & Modified from [45] \\
\hline & TseEPT7-F & TAATACGACTCACTATAGGGATCGGGCAAACCCTCAAC & \\
\hline \multicolumn{4}{|l|}{ A Primers for $q-R T-P C R$} \\
\hline \multirow[t]{2}{*}{ Argonaute 1} & AGO-1qPCR-F & CAACTGCTCGTTCGGCTCCA & This study \\
\hline & AGO-1qPCR-R & GGCAAAACTCGTCCTCTTACTTCCA & \\
\hline \multirow[t]{2}{*}{ Argonaute 2} & AGO-2qPCR-F & CGTTGGATGATGGCACAAAGATG & This study \\
\hline & AGO-2qPCR-R & GCTGCCTGATGTGATGCAATTC & \\
\hline \multirow[t]{2}{*}{ Argonaute 3} & AGO-3qPCR-F & GCACAACTAGCAGAGATGACAGATAC & This study \\
\hline & AGO-3qPCR-R & TGCAGGGCAATCTITTGGACAAT & \\
\hline \multirow[t]{2}{*}{ Dicer 2} & DCR-2qPCR-F & GTAGAGCGAAGATACACGGCTAAA & This study \\
\hline & DCR-2qPCR-R & CACCATAAATTGCGGCCTAATGAC & \\
\hline \multirow[t]{2}{*}{ Drosha } & DroshaqPCR-F & TCAAAACCAAGGACAGAGCGGA & This study \\
\hline & DroshaqPCR-R & GCAAACGGGGAAAAAGGCAAAC & \\
\hline \multirow[t]{2}{*}{ Tsetse EP } & TseEPqPCR-F & ACCGTTCGTTCGCTTIACTAC & Modified from [45] \\
\hline & TseEPqPCR-R & ACCAGCAGCCGTTTGACTIC & \\
\hline \multirow[t]{2}{*}{ GpSGHV (odv-e66) } & GpSGHVqPCR-F & CAAATGATCCGTCGTGGTAGAA & [3] \\
\hline & GpSGHVqPCR-F & AAGCCGATTATGTCATGGAAGG & \\
\hline \multirow{2}{*}{$\begin{array}{l}\text { GpSGHV (Maltodextrin glycosyltransferase, } \\
\text { tegument protein) }\end{array}$} & GpSGHV32F & ACGCTGAACTAAATTATCGTCATCTACACG & This study \\
\hline & GpSGHV31R & CACAGAATCGTCATCATCATCATCTACAGA & \\
\hline \multirow[t]{2}{*}{ GpSGHV (capsid protein) } & GpSGHV92F & TATATTGTAATCCACGACCGGAAACTGAAC & This study \\
\hline & GpSGHV91R & TCGGTAGGCGTGAATGAACGTITT & \\
\hline \multirow[t]{2}{*}{$\beta$-Tubulin (tsetse) } & Tse-TubqPCR-F & GATGGTCAAGTGCGATCCT & [66] \\
\hline & Tse-TubqPCR-R & TGAGAACTCGCCTTCTTCC & \\
\hline
\end{tabular}


sequence, (ii) selection of siRNA sequence with reduced off-target effects and (iii) elimination of near-perfect matched off-target genes. The identification of off-targets was performed by BLAST (BLASTn; e-value $\leq 10^{-2}$ ) search of VectorBase. Following identification of the siRNAs, primers for dsRNAs synthesis were designed to flank the most effective siRNAs based on the above-described steps and a T7 promoter sequence added on each primer (See Additional files 2 and 3).

\section{Synthesis of dsRNAs}

To generate dsRNA to knockdown $A G O 2$, total DNA was isolated from G. pallidipes using the Qiagen DNeasy Blood and Tissue kit (QIAGEN Inc., Valencia, CA). The extracted DNA was subsequently used to produce T7 tailed PCR amplicons of $A G O 2$ using primers designed to contain 5'-T7 promotor sequences (See Table 2). These primers allowed dsRNAs transcription using the Hiscribe T7 Quick high yield RNA synthesis kit (New England Biolabs, UK) according to the manufacturer's instructions. Template DNA was removed from the transcription reaction by DNase treatment, as described in the transcription kit. The synthesized dsRNAs were purified using MEGAclear columns (Ambion, ThermoFisher Scientific, USA) and eluted in $50 \mu \mathrm{l}$ nuclease free water. The tsetse EP gene, an immune response gene with extensive glutamic acid-proline dipeptide repeats, that has been successfully knocked down in tsetse, $[45,46]$ was used to assess the efficiency of the knockdown treatment (i.e. by measuring the expression of the tsetse EP gene).

\section{Injections of flies with GpSGHV and dsRNAs}

To investigate the impact of $A G O 2$ knockdown on GpSGHV infection, teneral G. pallidipes flies were divided into three groups each consisting of 40 females and 40 males and offered one blood meal. After $48 \mathrm{~h}$, two of three groups were injected with $4 \mu \mathrm{l}$ of either AGO-2 or tsetse EP dsRNAs $(2.5 \mu \mathrm{g} / \mu \mathrm{l}$ dsRNA in RNase free water) (See the procedure in Additional file 4). The selection of this dsRNA dose was optimized for effective knockdown based on previous bioassays on dsRNA-mediated gene knockdown in tsetse flies $[45,46]$. The third group of flies (an additional negative control) was injected with RNase-free water. For the injections, flies were anaesthetized by chilling ( $\sim \mathrm{min})$ on ice, and subsequently injected in the dorsolateral surface of the thorax. Five days after the dsRNAs/RNase-free water injections, half of the injected flies (20 females and 20 males) from each group were injected with $2 \mu \mathrm{l}$ of the virus suspension as described above, while the other half were injected with PBS. This time point (i.e. 5 days post dsRNA injection) was selected because successful gene knockdown in tsetse has been shown to occur after $~ 3$ dpi [46], implying that the $5 \mathrm{dpi}$ in our case ensured that the virus was injected after successful knockdown. To monitor the impact of $A G O 2$ knockdown on GpSGHV infection, 3 females and 3 males were sampled from each of the above described treatment groups at $1 \mathrm{~h}$ post injection, and at 7 , 14 and $21 \mathrm{dpi}$. The samples were stored at $-20{ }^{\circ} \mathrm{C}$ until further analysis as described below.

\section{Analysis of the impacts of $A G O 2$ knockdown on GpSGHV replication}

To assess the effect of $A G O 2$ knockdown of GpSGHV replication, total RNA was extracted and cDNA synthesized as described above from the frozen fly samples collected from different time points post dsRNA and virus injection. The efficiency of gene knockdowns was assessed by quantifying (by RT-qPCR) AGO2 and tsetse EP gene transcripts using the qPCR primer sets listed in Table 2. The impact of $A G O 2$ knockdown on GpSGHV infection was assessed by RT-qPCR quantification of mRNA transcripts of the selected conserved GpSGHV genes; the per os infectivity odv-e66 (SGHV005) gene, DNApol (SGHV079) gene involved in DNA replication, a tegument gene (SGHV038) and capsid gene (SGHV091) [59,60]. Note that a clear correlation between the GpSGHVodv-e66 gene transcripts and the total virus copy numbers has been previously reported [3], which may demonstrate the impact of $A G O 2$ knockdown on virus replication.

\section{Statistical analysis}

All quantitative RT-qPCR results were representative of at least three independent biological experiments, each with three technical replicates. Statistical differences in the expression of the above described host and viral genes between the different treatments and the controls were performed with RStudio v1.0.143 [61] (R v3.4.0 [62]) using the packages lattice v0.20-35 [63] and MASS v7.3.47 [64] The obtained data were visualized using the ggplot2 v2.2.1 package [65] available within the RStudio platform. Data was checked for normality and transformed where necessary using the Box-Cox routine. The data was log transformed where the confidence interval of lambda includes 0 and transformed with $\left(x^{\lambda}-1\right) / \lambda$ in other cases. T-tests were used for the comparison of RT-qPCR data.

\section{Additional files}

\footnotetext{
Additional file 1: Regression parameters applied in the statistical analysis. For each regression line (column 2) found in the figures (column 1), the confidence interval of lambda values (column 3) obtained based on the Box-Cox routine to determine the method of transformation (column 4) of the data, the intercept values (column 5), the t value (column 6) the $P$ values (column 7) and the degrees of freedom (D.F) in column 8. (DOCX 23 kb)

Additional file 2: Result of AGO2 dsRNA design and off-target prediction. A). AGO2 mRNA sequence; the primers flanking the knockdown sequence are highlighted in cyan, predicted siRNAs in grey and GPCR primers in yellow. (B) Shows a graphical view of effective siRNAs candidates. (TIF $9175 \mathrm{~kb}$ )
} 
Additional file 3: Result of tsetse EP dsRNA design and off-target prediction. A). Tsetse EP mRNA sequence; the primers flanking knockdown sequence are highlighted in cyan, predicted siRNAs in grey and gPCR primers in yellow. (B) Shows a graphical view of effective siRNAs candidates. (TIF $8491 \mathrm{~kb}$ )

Additional file 4: Step by step procedure to determine the effect of Knock-down of $A G O 2$ on virus infection in G. pallidipes. Teneral G. pallidipes flies were collected and offered one blood meal. $48 \mathrm{~h}$ later the flies were divided onto three groups and injected with $4 \mu \mathrm{AGO2}$ dsRNAs, tsetse EP dsRNAs or RNase-free water. Five days later, each of the 3 groups was divided into two and each injected with either $2 \mu \mathrm{l}$ of the virus suspension or with PBS. Three females and 3 males were sampled from each of the described treatments at $1 \mathrm{~h}$ post injection, and at 7, 14 and 21 days post injection to determine the effect of $\mathrm{AGO} 2$ knockdown on virus infection. (TIF $1030 \mathrm{~kb}$ )

\section{Abbreviations}

AGO: Argonaute; AW-IPM: area-wide integrated pest management; DCR: Dicer; DCV: Drosophila C virus; DsRNA: double stranded RNA; FHV: Flock house virus; GpSGHV: Glossina pallidipes salivary gland hypertrophy virus; HearNPV: Helicoverpa armigera single nucleopolyhedrovirus; Imd: immune deficiency; IPCL: Insect Pest Control Laboratory; JAK-STAT: Janus kinase/signal transducers and activators of transcription; miRNA: microRNA; piRNA: Piwiinteracting RNA; RISC: RNA induced silencing complex; RNAi: RNA interference; SGH: salivary gland hypertrophy; SINV: Sindbis virus; siRNA: short interfering RNA; vsiRNAs: virus-derived siRNAs

\section{Acknowledgements}

The authors acknowledge Prof. Serap Aksoy of Yale University for insightful discussions during the conception of the study and Hasim Mohammed, Carmen Marin and Henry Adun of the Joint FAO/IAEA Insect Pest Control Laboratory (IPCL), Seibersdorf, Austria for technical assistance.

\section{Funding}

This work was financially supported by the Joint FAO/AEEA Division of Nuclear Techniques in Food and Agriculture, Vienna, Austria (CRP \#D42015) and Wageningen University (WU). Both FAO/IAEA Division and WU participated in the design of the study, provided the resources for running of the experiments and writing of the manuscript.

\section{Availability of data and materials}

Materials described in the manuscript, including all relevant raw data, are deposited in this link https://dataverse.harvard.edu/dataset.xhtml?persistentld =doi:10.7910/DVN/ZN20Q6.

\section{About this supplement}

This article has been published as part of BMC Microbiology Volume 18 Supplement 1, 2018: Enhancing Vector Refractoriness to Trypanosome Infection. The full contents of the supplement are available online at https://bmcmicro biol.biomedcentral.com/articles/supplements/volume-18-supplement-1.

\section{Authors' contributions}

VJM, KHM and AMMA conceived the study. AMMA, VJM, KHM and VOMM: designed, supervised the research and writing of the manuscript. MIK, AGP, AMMA: conducted the experiments, collected and analyzed data and prepared the figures. MIK, AGP, MJBV, KHM, VJM, VOMM, AMMA: participated in the writing of the manuscript. All authors have read and agreed to the contents of the final manuscript and confirm that the manuscript conforms to the journal's policies.

\section{Ethics approval and consent to participate}

Not applicable.

\section{Consent for publication}

Not applicable.

\section{Competing interests}

The authors declare that they have no competing interests.

\section{Publisher's Note}

Springer Nature remains neutral with regard to jurisdictional claims in published maps and institutional affiliations.

\section{Author details}

${ }^{1}$ Insect Pest Control Laboratory, Joint FAO/IAEA Programme of Nuclear Techniques in Food and Agriculture, International Atomic Energy Agency, Vienna International Centre, P.O. Box 100, 1400 Vienna, Austria. ${ }^{2}$ Laboratory of Virology, Wageningen University, 6708, PB, Wageningen, The Netherlands. ${ }^{3}$ Biotechnology Research Institute, Kenya Agricultural and Livestock Research Organization, P.O Box 57811, Loresho, Nairobi, Kenya.

Published: 23 November 2018

\section{References}

1. Abd-Alla AM, Vlak JM, Bergoin M, Maruniak JE, Parker A, Burand JP, Jehle JA, Boucias DG. Hytrosaviridae: a proposal for classification and nomenclature of a new insect virus family. Arch Virol. 2009;154(6):909-18.

2. Abd-Alla AMM, Boucias DG, Bergoin M. Hytrosaviruses: structure and genomic properties. In: Virology I, editor. Asgari SJ, K.N.: caister academic press: Norfolk; 2010. p. 103-21.

3. Abd-Alla AMM, Cousserans F, Parker AG, Jridi C, Bergoin M, Robinson AS Quantitative PCR analysis of the salivary gland hypertrophy virus (GPSGHV) in a laboratory colony of Glossina pallidipes. Virus Res. 2009:139(1):48-53.

4. Kariithi HM, van Oers MM, Vlak JM, Vreysen MJ, Parker AG, Abd-Alla AM. Virology, epidemiology and pathology of Glossina hytrosavirus, and its control prospects in laboratory colonies of the tsetse fly, Glossina pallidipes (Diptera; Glossinidae). Insects. 2013;4(3):287-319.

5. Kariithi HM, Ahmadi M, Parker AG, Franz G, Ros VID, Haq I, Elashry AM, Vlak $J M$, Bergoin $M$, Vreysen MJB, et al. Prevalence and genetic variation of salivary gland hypertrophy virus in wild populations of the tsetse fly Glossina pallidipes from southern and eastern Africa. J Invertebr Pathol. 2013; 112(Supplement 1):S123-32.

6. Abd-Alla AMM, Kariithi HM, Mohamed AH, Lapiz E, Parker AG, Vreysen MJB. Managing hytrosavirus infections in Glossina pallidipes colonies: feeding regime affects the prevalence of salivary gland hypertrophy syndrome. PLoS One. 2013;8(5):e61875.

7. Alemu T, Kapitano B, Mekonnen S, Aboset G, Kiflom M, Bancha B, Woldeyes G, Bekele K, Feldmann U. Area-wide control of tsetse and trypanosomosis: Ethiopian experience in the southern Rift Valley. In: Vreysen MJB, Robinson AS, Hendrichs J, editors. Area-wide control of insect pests: from research to field implementation. Dordrecht: Springer Netherlands; 2007. p. 325-35.

8. Boldogh I, Albrecht T, Porter DD. Persistent viral infections. In: Baron S, editor. Med Microbiol. 4th ed: Galveston, University of Texas Medical Branch at Galveston; 1996. (Chapter 46).

9. Goic B, Saleh M-C. Living with the enemy: viral persistent infections from a friendly viewpoint. Curr Opin Microbiol. 2012;15(4):531-7.

10. Abd-Alla AMM, Kariithi HM, Parker AG, Robinson AS, Kiflom M, Bergoin $M$, Vreysen MJB. Dynamics of the salivary gland hypertrophy virus in laboratory colonies of Glossina pallidipes (Diptera: Glossinidae). Virus Res. 2010;150(1-2):103-10.

11. Kariithi HM, Meki IK, Boucias DG, Abd-Alla AM. Hytrosaviruses: current status and perspective. Curr. Opin. Insect Sci. 2017;22:71-8.

12. van Rij RP. Virus meets RNAi. Symposium on antiviral applications of RNA interference. EMBO Rep. 2008;9(8):725-9.

13. Kingsolver $M B$, Huang Z, Hardy RW. Insect antiviral innate immunity: pathways, effectors, and connections. J Mol Biol. 2013;425(24):4921-36

14. Burand JP, Hunter WB. RNAi: future in insect management. J Invertebr Pathol. 2013;112:568-74.

15. Bronkhorst AW, van Cleef KWR, Vodovar N, Ince IA, Blanc H, Vlak JM, Saleh M-C, van Rij RP. The DNA virus invertebrate iridescent virus 6 is a target of the Drosophila RNAi machinery. Proc Natl Acad Sci U S A. 2012;109(51):3604-13.

16. Ding SW. RNA-based antiviral immunity. Nat Rev Immunol. 2010;10(9):632-44.

17. Lan $H$, Chen H, Liu Y, Jiang C, Mao Q, Jia D, Chen Q, Wei T. Small interfering RNA pathway modulates initial viral infection in midgut epithelium of insect after ingestion of virus. J Virol. 2016;90(2):917-29.

18. Skalsky RL, Cullen BR. Viruses, microRNAs, and host interactions. Annu Rev Microbiol. 2010;64:123-41.

19. Asgari S. MicroRNA functions in insects. Insect Biochem Mol Biol. 2013; 43(4):388-97. 
20. Kincaid RP, Sullivan CS. Virus-encoded microRNAs: an overview and a look to the future. PLoS Pathog. 2012;8(12):e1003018.

21. Nandety RS, Kuo Y-W, Nouri S, Falk BW. Emerging strategies for RNA interference (RNAi) applications in insects. Bioengineered. 2015;6(1):8-19.

22. Weick E-M, Miska EA. piRNAs: from biogenesis to function. Development. 2014;141(18):3458

23. Miesen P, Joosten J, van Rij RP. PIWls go viral: arbovirus-derived piRNAs in vector mosquitoes. PLoS Pathog. 2016:12(12):e1006017.

24. Carmell MA, Hannon GJ. RNase III enzymes and the initiation of gene silencing. Nat Struct Mol Biol. 2004;11(3):214-8.

25. Tomoyasu Y, Miller SC, Tomita S, Schoppmeier M, Grossmann D, Bucher G. Exploring systemic RNA interference in insects: a genome-wide survey for RNAi genes in Tribolium. Genome Biol. 2008;9(1):R10.

26. Zambon RA, Vakharia VN, Wu LP. RNAi is an antiviral immune response against a dsRNA virus in Drosophila melanogaster. Cell Microbiol. 2006;8(5):880-9.

27. Kemp C, Mueller S, Goto A, Barbier V, Paro S, Bonnay F, Dostert C, Troxler L, Hetru C, Meignin C, et al. Broad RNA interference-mediated antiviral immunity and virus-specific inducible responses in Drosophila. J Immunol. 2013;190(2):650-8

28. Jayachandran B, Hussain M, Asgari S. RNA interference as a cellular defense mechanism against the DNA virus baculovirus. J Virol. 2012; 86(24):13729-34.

29. Bronkhorst AW, van Cleef KWR, Venselaar $H$, van Rij RP. A dsRNA-binding protein of a complex invertebrate DNA virus suppresses the Drosophila RNAi response. Nucleic Acids Res. 2014;42(19):12237-48.

30. Sabin LR, Zheng Q, Thekkat P, Yang J, Hannon GJ, Gregory BD, Tudor M, Cherry S. Dicer-2 processes diverse viral RNA species. PLoS One. 2013;8(2):e55458.

31. Galiana-Arnoux D, Dostert C, Schneemann A, Hoffmann JA, Imler J-L. Essential function in vivo for Dicer-2 in host defense against RNA viruses in Drosophila. Nat Immunol. 2006;7(6):590-7.

32. Goic B, Vodovar N, Mondotte JA, Monot C, Frangeul L, Blanc H, Gausson V, Vera-Otarola J, Cristofari G, Saleh M-C. RNA-mediated interference and reverse transcription control the persistence of RNA viruses in the insect model Drosophila. Nat Immunol. 2013:14(4):396-403.

33. Gammon DB, Mello CC. RNA interference-mediated antiviral defense in insects. Curr Opin Insect Sci. 2015:8:111-20.

34. Bronkhorst AW, van Rij RP: The long and short of antiviral defense: small RNA-based immunity in insects. Curr. Opin. Virol. 2014, 7:19-28.

35. Boucias DG, Kariithi HM, Bourtzis K, Schneider DI, Kelley K, Miller WJ, Parker AG, Abd-Alla AMM. Transgenerational transmission of the Glossina pallidipes hytrosavirus depends on the presence of a functional symbiome. PLoS One. 2013;8(4):e61150

36. Carmell MA, Xuan Z, Zhang MQ, Hannon GJ. The Argonaute family: tentacles that reach into RNAi, developmental control, stem cell maintenance, and tumorigenesis. Genes Dev. 2002;16(21):2733-42.

37. Lee YS, Nakahara K, Pham JW, Kim K, He Z, Sontheimer EJ, Carthew RW. Distinct roles for Drosophila Dicer-1 and Dicer-2 in the siRNA/miRNA silencing pathways. Cell. 2004;117(1):69-81.

38. Wang X-H, Aliyari R, Li W-X, Li H-W, Kim K, Carthew R, Atkinson P, Ding S-W. RNA interference directs innate immunity against viruses in adult Drosophila. Science. 2006;312(5772):452-4.

39. Gu S, Jin L, Huang Y, Zhang F, Kay MA. Slicing-independent RISC activation requires the argonaute PAZ domain. Curr Biol. 2012;22(16):1536-42.

40. Meister G, Tuschl T. Mechanisms of gene silencing by double-stranded RNA. Nature. 2004:431(7006):343-9.

41. Parker JS, Barford D. Argonaute: a scaffold for the function of short regulatory RNAs. Trends Biochem Sci. 2006;31(11):622-30.

42. Keene KM, Foy BD, Sanchez-Vargas I, Beaty BJ, Blair CD, Olson KE. RNA interference acts as a natural antiviral response to O'nyong-nyong virus (Alphavirus; Togaviridae) infection of Anopheles gambiae. Proc Natl Acad Sci U S A. 2004;101(49):17240-5.

43. Huvenne $H$, Smagghe G. Mechanisms of dsRNA uptake in insects and potential of RNAi for pest control: a review. J Insect Physiol. 2010;56(3):227-35.

44. Swevers L, Smagghe G. Use of RNAi for control of insect crop pests. In: Arthropod-plant interactions: novel insights and approaches for IPM. Edited by Smagghe G, Diaz I, vol. 14. Dordrecht: Springer Netherlands; 2012. p. 177-97.

45. Walshe DP, Lehane SM, Lehane MJ, Haines LR. Prolonged gene knockdown in the tsetse fly Glossina by feeding double stranded RNA. Insect Mol Biol. 2009;18(1):11-9.

46. Haines $L R$, Lehane SM, Pearson TW, Lehane MJ. Tsetse EP protein protects the fly midgut from trypanosome establishment. PLoS Pathog. 2010;6(3):e1000793.
47. van Rij RP, Saleh MC, Berry B, Foo C, Houk A, Antoniewski C, Andino R. The RNA silencing endonuclease Argonaute 2 mediates specific antiviral immunity in Drosophila melanogaster. Genes Dev. 2006;20(21):2985-95.

48. Costa A, Jan E, Sarnow P, Schneider D. The IMD pathway is involved in antiviral immune responses in Drosophila. PLoS One. 2009;4(10):e7436.

49. Sabin LR, Hanna SL, Cherry S. Innate antiviral immunity in Drosophila. Curr Opin Immunol. 2010;22(1):4-9.

50. Fullaondo A, Lee SY. Regulation of Drosophila-virus interaction. Dev Comp Immunol. 2012;36(2):262-6.

51. Rechavi O. "Guest list" or "black list"? Heritable small RNAs as immunogenic memories. Trends Cell Biol. 2014;24(4):212-20.

52. Feldmann U. Guidelines for the rearing of tsetse flies using the membrane feeding technique. In: Ochieng'-Odero JPR, editor. Techniques of insect rearing for the development of integrated pest and vector management strategies. Nairobi: ICIPE Science Press; 1994. p. 449-71.

53. Giraldo-Calderón Gl, Emrich SJ, MacCallum RM, Maslen G, Dialynas E, Topalis P, Ho N, Gesing S, the VectorBase C, Madey G, et al. VectorBase: an updated bioinformatics resource for invertebrate vectors and other organisms related with human diseases. Nucleic Acids Res. 2015;43(Database issue):D707-13.

54. International Glossina Genome Initiative. Genome sequence of the tsetse fly (Glossina morsitans): vector of African trypanosomiasis. Science. 2014; 344(6182):380-6.

55. De Castro E, Sigrist CJA, Gattiker A, Bulliard V, Langendijk-Genevaux PS, Gasteiger E, Bairoch A, Hulo N. ScanProsite: detection of PROSITE signature matches and ProRule-associated functional and structural residues in proteins. Nucleic Acids Res. 2006;34(Web Server):W362-5.

56. Hall T. BioEdit: an important software for molecular biology. GERF Bulletin of Biosciences. 2011:2:30-61.

57. Tamura K, Stecher G, Peterson D, Filipski A, Kumar S. MEGA6: molecular evolutionary genetics analysis version 6.0. Mol Biol Evol. 2013;30(12):2725-9.

58. Naito Y, Ui-Tei K. siRNA design software for a target gene-specific RNA interference. Front Genet. 2012;3:102.

59. Abd-Alla AMM, Cousserans F, Parker AG, Jehle JA, Parker NJ, Vlak JM, Robinson AS, Bergoin M. Genome analysis of a Glossina pallidipes salivary gland hypertrophy virus reveals a novel, large, double-stranded circular DNA virus. J Virol. 2008;82(9):4595-611.

60. Abd-Alla AMM, Kariithi HM, Cousserans F, Parker NJ, İnce IA, Scully ED, Boeren S, Geib SM, Mekonnen S, Vlak JM, et al. Comprehensive annotation of Glossina pallidipes salivary gland hypertrophy virus from Ethiopian tsetse flies: a proteogenomics approach. J Gen Virol. 2016;97(4):1010-31.

61. RStudio T. RStudio: integrated development environment for R. RStudio, Inc. Boston. In: MA; 2015

62. R-Core T. R: a language and environment for statistical computing. Vienna, Austria: R Foundation for statistical computing; 2015.

63. Sarkar D. Lattice: multivariate data visualization with R. New York: Springer; 2008

64. Venables WN, Ripley BD. Modern applied statistics with S. 4th ed. New York: Springer; 2002

65. Wickham H. Ggplot2: elegant graphics for data analysis. New York: Springer; 2009

66. Caljon G, Broos K, De Goeyse I, De Ridder K, Sternberg JM, Coosemans M, De Baetselier P, Guisez Y, Van Den Abbeele J. Identification of a functional Antigen5-related allergen in the saliva of a blood feeding insect, the tsetse fly. Insect Biochem Mol Biol. 2009;39(5-6):332-41.

Ready to submit your research? Choose BMC and benefit from:

- fast, convenient online submission

- thorough peer review by experienced researchers in your field

- rapid publication on acceptance

- support for research data, including large and complex data types

- gold Open Access which fosters wider collaboration and increased citations

- maximum visibility for your research: over $100 \mathrm{M}$ website views per year

At BMC, research is always in progress.

Learn more biomedcentral.com/submission 